\title{
REVIEWS
}

\section{MYELIN-ASSOCIATED INHIBITORS OF AXONAL REGENERATION IN THE ADULT MAMMALIAN CNS}

\begin{abstract}
Marie T. Filbin
Recent studies have expanded our knowledge, at the molecular level, of how myelin inhibits axonal regeneration after injury to the mammalian central nervous system. Several inhibitors have been identified that seem to signal inhibition through the same receptor complex. New molecular information has also accumulated on how the neuron can be changed intrinsically to overcome myelin inhibitors. Together, these important advances in the field have identified many new targets for therapeutic intervention to encourage nerve regeneration after spinal cord or brain injury.
\end{abstract}

Hieroglyphs of the ancient Egyptians provide the earliest known reference to the fact that, unlike the peripheral nervous system (PNS) the adult mammalian central nervous system (CNS) does not spontaneously regenerate after injury (BOX 1). The Edwin Smith surgical papyrus, which dates back to $1550 \mathrm{BC}$, states that "If you examine a man with a neck injury ... and find he is without sensation in both arms and both legs, and unable to move them, and he is incontinent of urine ... it is due to the breaking of the spinal cord caused by dislocation of a cervical vertebra. This is a condition which cannot be treated".

We now know that there are two main obstacles to regeneration after injury: inhibitors within myelin and the formation of a glial scar ${ }^{1-3}$. The scar is formed by astrocytes, which change their morphology to present a physical barrier to growth and also upregulate several extracellular-matrix-associated inhibitors of regeneration. Before the scar matures, however, myelin seems to be the predominant source of growth inhibition.

A study by David and colleagues ${ }^{4}$ confirmed the

Department of Biological Sciences, Hunter College, City University of New York, 695 Park Avenue, New York, New York 10021, USA. e-mail: Filbin@genectr.hunter.cuny. $e d u$ doi:10.1038/nrn1195 two things: first, immediately after injury the main impediments to regeneration are inhibitors in myelin, and second, there is a 'window of opportunity', before the scar is mature, when regeneration can proceed as long as myelin inhibitors are blocked/neutralized.

Given the recent impressive advances in our understanding of how myelin inhibitors work, the time is right for a review of strategies that have the potential to overcome myelin inhibitors, and could thereby encourage spinal cord regeneration in vivo. In this review I will describe what is known about the individual myelin inhibitors, whether there is redundancy in their activities, and what signalling pathways are involved in bringing about inhibition. Finally, I will describe recent studies where activation of parallel signalling pathways has been shown to overcome inhibition by changing the intrinsic growth state of the neuron.

\section{Inhibitors of regeneration in myelin}

Nogo. Ramón y Cajal was the first person to suggest that white matter could 'block' regeneration in the $\mathrm{CNS}^{5}$. Subsequent studies confirmed that this was probably true ${ }^{6,7}$, although it was not until the definitive work of Schwab and his colleagues in the late 1980s that we were given a molecular insight into the mechanism of inhibition $^{8,9}$. The IN-1 monoclonal antibody, which was raised against a fraction of myelin that did not support neurite extension, allowed axons to grow on myelin both 


\section{Box 1 Regeneration in the PNS versus the CNS}

Unlike the central nervous system (CNS), the adult mammalian peripheral nervous system (PNS) readily regenerates after injury. This is not because peripheral myelin is 'permissive' for re-growth, as myelin-associated glycoprotein (Mag) and oligodendrocyte myelin glycoprotein $(\mathrm{Omg})$, as well as Nogo receptor $(\mathrm{Ngr})$ and p75 neurotrophin receptor ( $\left.\mathrm{p} 75^{\mathrm{NTR}}\right)$, are present in the PNS. Rather, macrophages and Schwann cells rapidly clear myelin after injury. Also, the Schwann cells go on to dedifferentiate, and they downregulate all myelin proteins so that they become permissive for regeneration ${ }^{101}$. This rapid change in the PNS environment is clearly responsible for the difference between the PNS and the CNS in regenerative capacity.

It has long been assumed that a stronger immune response is triggered in the PNS than in the CNS after injury. That is to say, fewer macrophages are recruited to the CNS than the PNS injury site, and this might account for the slow removal of myelin in the CNS. Indeed, one strategy to encourage regeneration in the CNS has been to introduce macrophages that have been activated with either PNS myelin or optic nerve fragments into the injury site ${ }^{102}$. The prediction was that these 'pre-activated' macrophages would phagocytose myelin and other debris as rapidly as in the PNS, thereby creating a permissive environment for regeneration. Surprisingly however, a recent study, in which the number and activation state of macrophages recruited to the PNS and the CNS after injury were compared, showed that if anything, more macrophages in a more activated state were present in the CNS than in the PNS ${ }^{103}$.

So, why is myelin not rapidly removed from the CNS? The answer might lie in the difference in behaviour between Schwann cells and oligodendrocytes. Unlike Schwann cells, oligodendrocytes continue to express myelin proteins - including inhibitors after injury and they do not engulf myelin debris. If this reasoning is correct, and the activation of the immune system is comparable after CNS and PNS injury, it is doubtful that introduction of exogenous activated macrophages into the injured CNS could compensate for the inability of oligodendrocytes to remove myelin.

\section{LECTINS}

Sugar-binding proteins that tend to agglutinate cells.

PARANODAL LOOPS

Concertina-shaped folds of myelin, which flank the nodes of Ranvier.

SCHMIDT-LANTERMAN INCISURES

Funnel-shaped interruptions in the myelin sheath that were shown by electron microscopy to correspond to strands of cytoplasm separating two otherwise fused myelinating cell membranes.

GLYCOSYL PHOSPHATIDYLINOSITOL A post-translational modification, the function of which is to attach proteins to the exoplasmic leaflet of membranes, possibly to specific domains therein. The anchor is made of one molecule of phosphatidylinositol to which a carbohydrate chain is linked through the C6 hydroxyl of the inositol, and is attached to the protein through an ethanolamine phosphate moiety. in culture and in $v i v o^{10}$. This was the first indication that specific molecules were involved and that the effect was not simply one of general non-permissiveness.

Despite intense work, it was not until a decade later that an antigen for the IN-1 antibody was identified. Three groups independently cloned an antigen of the IN-1 antibody, which was named Nogo by Schwab ${ }^{11-13}$. Nogo exists in three isoforms - A, B and C - and is a member of the reticulon family, which comprises proteins that usually associate with the endoplasmic reticulum (FIG. 1). Indeed, Nogo-A, the isoform that is enriched in oligodendrocytes, mostly associates with the endoplasmic reticulum. However, it has also been seen on
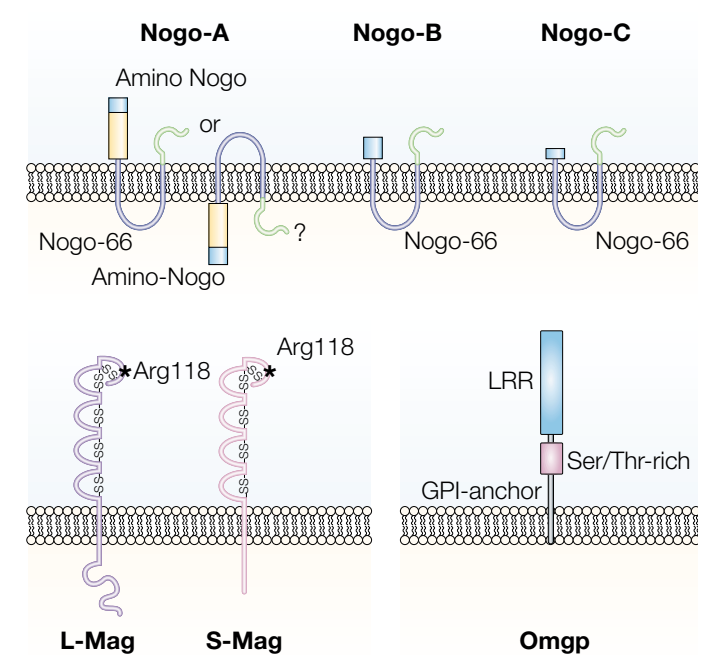

the oligodendrocyte surface and on the innermost loop of the myelin membrane, where it could make contact with the axon ${ }^{14,15}$.

All three Nogo isoforms have a common carboxyl (C) terminus, which contains sequences that are similar in all reticulons. Nogo-A, however, has a unique amino $(\mathrm{N})$ terminus and at least two inhibitory domains ${ }^{11-13}$. One of these domains (Nogo-66) is carried by a 66-amino-acid sequence, which is common to all three isoforms, and the second domain (amino-Nogo) is unique to the Nogo-Aspecific $\mathrm{N}$ terminus. The most common topology of Nogo-A in the membrane places Nogo-66 outside the cell, and the $\mathrm{N}$ - and C-terminals in the cytoplasmic compartment ${ }^{12}$. A second topology has also been proposed whereby amino-Nogo is extracellular, and it has been suggested that the two different topologies might coexist simultaneously ${ }^{11-14}$. This issue remains to be resolved, but Nogo-66 and amino-Nogo both induce growth cone collapse, regardless of the topology. Furthermore, it is conceivable that once myelin/oligodendrocytes are damaged by injury, both domains would be exposed to make contact with axons that are attempting to regenerate. If so, Nogo-A in the endoplasmic reticulum and any cytoplasmic sequences would now become exposed to the extracellular environment.

Myelin-associated glycoprotein. Although IN-1 had long been known to recognize a putative myelin inhibitor of regeneration, Nogo was not the first myelin inhibitor to be described. In 1994, a well-known myelin protein, myelin-associated glycoprotein (Mag), was shown to be a potent inhibitor of neurite outgrowth in culture ${ }^{16,17}$. Interestingly, young neurons are not inhibited by Mag; in fact, their growth is promoted in most cases ${ }^{17-21}$. Therefore, Mag seems to be bifunctional, and all neurons that have been studied to date switch their response to Mag from promotion to inhibition with development. The age at which the switch occurs is specific to the particular neuron type, and the ability of young neurons to grow on Mag (and on myelin in general) correlates with their ability to regenerate spontaneously in vivo ${ }^{18}$ (see later in text)

Figure 1 | Structures of three inhibitors of axonal regeneration identified in myelin. Nogo exists in three isoforms $-\mathrm{A}, \mathrm{B}$ and $\mathrm{C}-$ and their hypothesized topologies are shown here. Sequences that are common to all three isoforms are shown in blue and green. Only Nogo-A is enriched in oligodendrocytes, and it carries two inhibitory domains, one in Nogo-66 that is common to all three isoforms and one in the amino terminus - amino-Nogo - that is unique to Nogo-A. Nogo-A has been proposed to adopt two topologies, depending on whether Nogo-66 or amino-Nogo is extracellular. Myelin-associated glycoprotein (Mag) exists in large $(\mathrm{L})$ and small $(\mathrm{S})$ isoforms, which differ only in their cytoplasmic sequences. Mag carries five immunoglobin (lg)-like domains in its extracellular sequences and the first lg-domain adopts an unusual conformation by folding over the second lgdomain. The sialic acid-binding site on Mag is Arg118 in the first Ig-domain. Oligodendrocyte myelin glycoprotein (Omgp) is a glycosyl phosphatidylinositol (GPI)-linked protein that carries a leucine-rich repeat (LRR) region and a serine/threonine (Ser/Thr) rich region. 


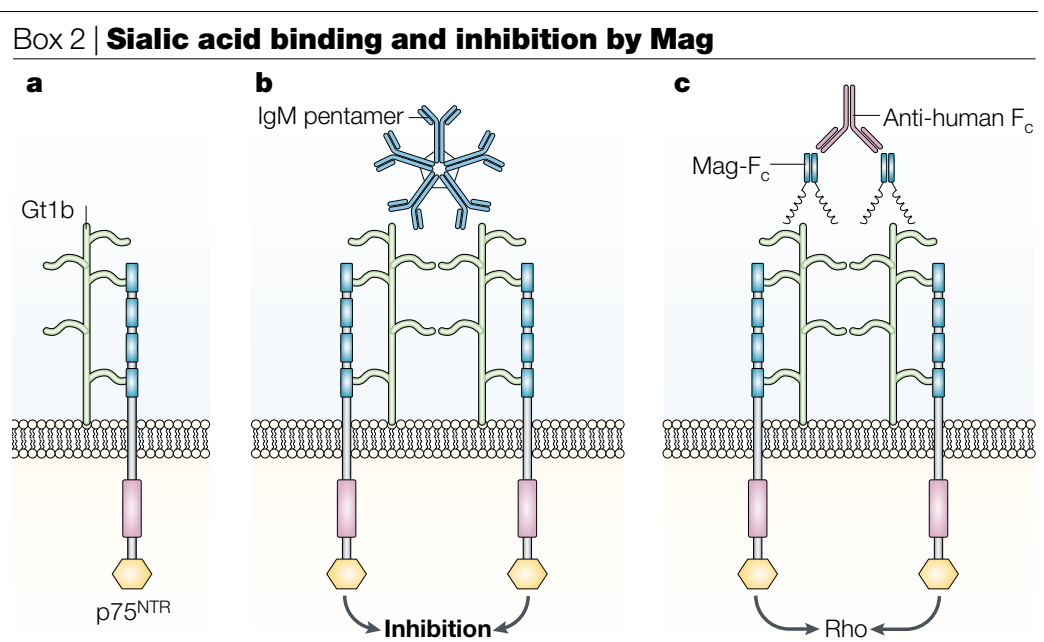

Myelin-associated glycoprotein (Mag) is a sialic acid-binding protein that specifically binds sialo-glycoproteins and sialo-glycolipids (gangliosides), preferably when the sialic acid residue is attached in a 2,3-O linkage, such as in $\mathrm{Gt1}^{24,104,105}$ (panel a). The sialic acidbinding site on Mag maps to arginine 118 (Arg118) in its first immunoglobulin (Ig)-like domain ${ }^{25}$. This arginine is conserved in other members of the Siglec family of molecules. When Arg118 of Mag is mutated, its sialic acid binding capabilities are lost, as is its ability to inhibit neurite outgrowth when in a soluble form. By contrast, when Arg1 18-mutated Mag is presented to neurons through expression by live cells, it inhibits neurite outgrowth as effectively as wild-type Mag, indicating that the sialic acid-binding site on Mag is distinct from its inhibition site. This is consistent with the recent finding that the binding of Mag to its receptor, $\mathrm{Ngr}$, is sialic acid-independent $\mathrm{t}^{35,36}$.

In apparent contradiction, other studies have reported that neurons from a mutant mouse that lacks complex gangliosides, and so Gt1b, are not inhibited by Mag ${ }^{106}$. How can this be the case when sialic acid-dependent binding seems to be essential for Mag to bring about inhibition? The answer might lie in how the assays were performed. When Mag is presented to the neurons as either a soluble molecule or an immobilized substrate, to exert inhibition it might require ganglioside binding to increase the avidity of the interactions. By contrast, when Mag is expressed by a live cell, strong interactions are not dependent on ganglioside binding. This suggestion is supported by two observations. First, if Gt1b is clustered using an anti-Gt1b IGM antibody (panel b), neurite outgrowth is inhibited without Mag's involvement, probably through a direct interaction of Gt1b with p75 neurotrophin receptor (p75 ${ }^{\mathrm{NTR}}$ ) (REFS 37,64,106). Second, in the absence of the glycosyl phosphatidylinositol (GPI)-linked Nogo receptor (Ngr), pre-clustered soluble Mag-immunoglobulin fusion protein (Mag- $\mathrm{F}_{\mathrm{c}}$ ), which in turn could cluster Gtlb (panel c), can still activate Rho, which implies inhibition ${ }^{63}$. These results show that clustering specific gangliosides in the absence of Mag and/or Ngr is sufficient to effect inhibition. Undoubtedly, Mag can and does bind gangliosides in a highly specific manner ${ }^{107}$. Indeed, binding to gangliosides is likely to potentiate and augment Mag's effect by inducing clustering of the signalling molecules. On the other hand, it seems that ganglioside involvement is only necessary for inhibition under certain conditions. The role of gangliosides in augmenting inhibition of axonal regeneration in vivo is still uncertain.

GM ANTIBODY An immunoglobulin molecule that consists of five immunoglobulin G-type monomers, joined together by J chains to form a cyclic pentamer. During an immune response, IgM is usually produced before IgG, and forms the first line of defence.
Mag is a member of the immunoglobulin (Ig) super family, and it contains five extracellular Ig-like domains $^{22,23}$ (FIG. 1). There are two isoforms of Mag that differ only in their cytoplasmic domains. It is also a sialic acid-binding protein, and its first four Ig-like domains are homologous to those of other sialic acid binding, Ig-like LECTINS (Siglecs), so it is also a member of the Siglec family $(\text { Siglec4a })^{24}$. The sialic acid binding capabilities of Mag are not essential for it to exert inhibition ${ }^{25}$, but they are likely to potentiate the effect (see later in text and BOX 2). Mag is found in both the CNS and the PNS, where it is located in the periaxonal membrane, and is therefore ideally placed to interact with an axonal receptor. Mag is also found in regions of uncompacted myelin, such as the PARANODAL LOOPS and the SCHMIDT-LANTERMAN INCISURES. In addition, in the PNS, Mag is found in the outermost myelin loop ${ }^{26,27}$.

Oligodendrocyte myelin glycoprotein. Recently, a third myelin-associated inhibitor was identified, which, like Mag, was recognized long before it was shown to be an inhibitor of axonal regeneration ${ }^{28}$. Oligodendrocyte myelin glycoprotein (Omgp) is a GLYCOSYL PHOSPHATIDYLINOSITOL (GPI)-linked protein and, contrary to the implication of the name, is expressed not only by oligodendrocytes, but also at high levels in various neurons ${ }^{29}$. It is also found in the PNS $^{30}$ (FIG.1). Omgp is a relatively minor component of myelin, and it is believed to be localized largely to the paranodal loops, next to the NODE OF RANVIER. Omgp contains a leucine-rich repeat (LRR) domain, followed by a C-terminal domain with serine/threonine repeats. In addition, Omgp is the protein that is responsible for the inhibition by the myelin fraction originally termed 'arretin ${ }^{31}$. Like Mag and Nogo, Omgp induces growth cone collapse and inhibits neurite outgrowth.

\section{Receptors for inhibitors of axonal growth}

After the identification of these inhibitors, the next step was to uncover the receptors that transduce their inhibitory signals across the membrane to the neuron. In 2001, using a soluble form of Nogo-66 to screen an expression library, Strittmatter and colleagues cloned a binding partner for Nogo-66, which they termed Nogo receptor (Ngr) ${ }^{32}$ (FIG. 2). Ngr is expressed, albeit at different levels, on the surface of various neurons ${ }^{33}$. It is an 85 $\mathrm{kDa}$ GPI-linked protein that contains a series of LRRs clustered in two groups - a series of eight, and a second series closer to the membrane-associated GPI-linked terminus of the protein (LRRCT, leucine rich repeats $\mathrm{C}$-terminal). These repeats are followed by a unique C-terminal sequence. Strittmatter et al. showed that direct interaction of Nogo-66 with Ngr was required to induce growth cone collapse, and that neurons that were unresponsive to Nogo-66 became responsive when they were transfected with an Ngr-expressing vector. Interestingly, Ngr is not the receptor for amino-Nogo - amino-Nogo does not bind Ngr, and blocking Ngr has no effect on amino-Nogo's ability to induce growth cone collapse.

Curiously, the Nogo-A sequence that is more restricted to the nervous system (amino-Nogo) interacts with non-neural cells, whereas the sequence that is widely expressed outside the nervous system (Nogo-66) does not. For example, amino-Nogo can block fibroblast spreading, whereas Nogo-66 cannot ${ }^{32,34}$, indicating that the amino-Nogo receptor is likely to be more widely expressed than Ngr. Whether this has any physiological relevance has yet to be determined, and the amino-Nogo receptor remains to be identified.

In an experiment that was originally designed to identify signal-transducing partner molecules for Ngr (see later in text), Strittmatter's group discovered a second ligand for this receptor. They used a soluble form of Ngr, consisting of the entire protein, to screen an expression 


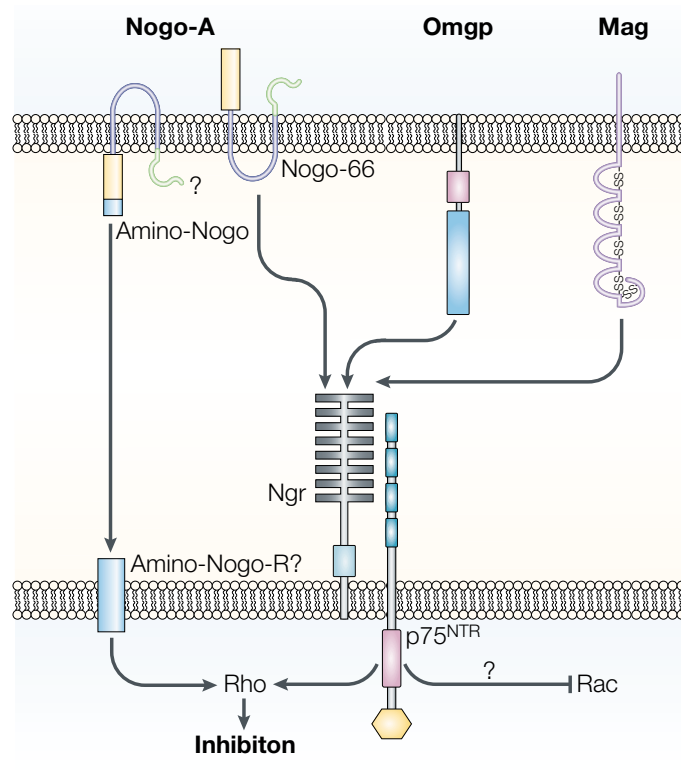

Figure 2 | Nogo-66, Mag and Omgp interact with the same receptor complex. Nogo-66, Myelin-associated glycoprotein (Mag) and oligodendrocyte myelin glycoprotein (Omgp) all interact with the glycosyl phosphatidylinositol-linked Nogo receptor (Ngr) to bring about inhibition of neurite outgrowth. Ngr contains two regions of LRRs - a cluster of eight together, and a series closer to the carboxyl terminus. Interaction of Mag with $\mathrm{Ngr}$ is independent of sialic acid binding. Ngr interacts with p75 ${ }^{\text {TTR }}$ to transduce the inhibitory signal across the membrane. The receptor for amino-Nogo is not known. However, aminoNogo, Nogo-66, Mag and Omgp all activate Rho to bring about inhibition. Mag has been shown to inactivate Rac, but it is not known whether this effect is required for inhibition.

library, and they found a new ligand that was shown to be $\mathrm{Mag}^{35}$. At the same time, our group had co-precipitated the two proteins and had also identified Ngr as a receptor for $\mathrm{Mag}^{36}$. Together, these two studies provided compelling evidence that Ngr is required for Mag to exert its inhibition. It was shown that a soluble form of Mag precipitates Ngr from primary neurons, that both a soluble form of Ngr and an Ngr antibody block Mag's inhibition of neurite outgrowth, and that a DOMINANT-NEGATIVE form of Ngr blocks Mag's inhibitory effects. Importantly, both studies also reported that the interaction of Mag with Ngr is independent of sialic acid binding, implying that this characteristic is not required for Mag to exert its inhibitory effects (BOX 2).

Around the time that Ngr was revealed to be a Mag receptor, He's group not only identified Omgp as a third myelin-associated inhibitor of axonal regeneration, but also showed that Omgp was yet another ligand for $\mathrm{Ngr}^{28}$. They showed that Omgp and Ngr co-precipitated, that a soluble form of Ngr blocked growth cone collapse by Omgp, and that a dominant-negative Ngr mutant blocked the inhibition of neurite outgrowth by Omgp. As there is no obvious sequence or domain similarity between Nogo-66, Mag and Omgp, it came as a surprise to find that they use the same receptor complex to signal inhibition.

Although Ngr is essential for Nogo-66, Mag and Omgp to exert their inhibitory effects, it cannot transduce the signal across the membrane, because it is a GPI-linked protein and therefore has no transmembrane or cytoplasmic domains. Consequently, a transmembrane 'transducing' partner was predicted to exist that would interact with Ngr. Even before the discovery that Ngr was a common receptor for all three myelin inhibitors, it was reported that the p75 neurotrophin receptor ( $\mathrm{p} 75^{\mathrm{NTR}}$ ) was the transducer for $\mathrm{Mag}^{37}$. It was convincingly shown that Mag did not inhibit neurite outgrowth from neurons from the $p 75^{\text {NTR }}$-knockout mouse. A direct interaction between Mag and p75 ${ }^{\mathrm{NTR}}$ could not be shown, but they were co-precipitated from neurons, implying that an additional component (now believed to be Ngr) created a bridge to allow them to interact. At the time, however, it was concluded that the GANGLIOSIDE Gtlb was responsible for this link, as it was found to be associated with $\mathrm{p} 75^{\mathrm{NTR}}$ and was known to bind to Mag. It is likely that gangliosides potentiate the inhibitory effects of Mag, but are not necessary for inhibition to occur (see BOX 2). It has now been shown that the $\mathrm{p} 75^{\mathrm{NTR}}$ can be precipitated by Mag, Nogo-66 or Omgp and that Ngr is present in the precipitate of each ${ }^{38,39}$ (FIG. 2). Furthermore, as well as being refractory to Mag's inhibitory effect on neurite outgrowth, neurons from $p 75^{\mathrm{NTR}-/}$ mice are not inhibited by either of the other two inhibitors, nor by myelin in general. Also, a dominant-negative form of $\mathrm{p} 75^{\mathrm{NTR}}$ blocks the inhibitory effects of the three individual inhibitors, and also of myelin.

With this explosion of knowledge about the molecular aspects of the inhibitory effects of myelin, an elaborate picture emerges, with the three main inhibitors that have been identified to date - Nogo-66, Mag and Omgp interacting with the same receptor complex, Ngr-p $75^{\text {NTR }}$ (FIG. 2). This implies that there is functional redundancy between these inhibitors; the presence of any one inhibitor is sufficient to prevent regeneration by activating an inhibitory signal through a single receptor complex. The redundancy is likely to be even greater if the three inhibitors have the same or overlapping binding sites on Ngr. From the recently-described crystal structure, several degenerate ligand-binding sites with the potential for high crossreactivity were identified on the Ngr molecule ${ }^{40}$. These putative degenerate binding domains present the possibility of interaction with such structurally diverse molecules as Nogo-66, Mag and Omgp.

The idea of redundancy can explain many of the previous results of in vivo experiments in which either Mag or Nogo was blocked or absent. In the Mag-knockout mouse, only a small amount of spontaneous axonal regeneration was recorded in one study, and none at all in another ${ }^{41,42}$. Likewise, an antibody to Nogo (IN-1) allowed only a small percentage of axons to regenerate, albeit over quite a distance ${ }^{10,43,44}$. Presumably, in all of these situations, the other ligands for Ngr are present and/or unblocked and can still prevent most axons from regenerating. By contrast, a peptide corresponding to a 40-amino-acid sequence in Nogo-66, which was predicted to block its interaction with $\mathrm{Ngr}$, allowed the majority of axons to regenerate over long distances ${ }^{45}$. However, this peptide could also be interfering with the ability of Mag and Omgp to bind to Ngr. 


\begin{tabular}{lllr}
\hline \multicolumn{2}{l}{ Table 1 | Summary of Nogo knockouts } & & Reference \\
$\begin{array}{l}\text { Targeted Nogo } \\
\text { genes }\end{array}$ & $\begin{array}{l}\text { Nogo isoforms } \\
\text { expressed }\end{array}$ & $\begin{array}{l}\text { Observed } \\
\text { regeneration }\end{array}$ & 48 \\
Nogo- $A,-B$ and $-C$ & 0 & 0 & 48 \\
Nogo-A and $-B$ & Nogo-C & 0 & 47 \\
Nogo-A & Nogo-B, Nogo-C & Limited sprouting & 46 \\
Nogo-A & Nogo-C & Limited regeneration & 4 \\
\hline
\end{tabular}

A blow was dealt to this satisfying redundancy model when the Nogo isoforms were knocked out in different combinations $s^{46-48}$. When expression of Nogo-A and Nogo-B was lost, Strittmatter and colleagues observed limited regeneration in around half of the resulting animals $^{46}$ (TABLE 1). The ability to regenerate spontaneously was only apparent in young mice, and was lost with age. In this study, a GENE TRAP insertion was targeted to an exon in Nogo-A, which had been targeted by Schwab using a more conventional strategy. Schwab had reported that when only Nogo-A is knocked out, there is compensatory upregulation of Nogo-B and only limited sprouting after injury ${ }^{47}$. The lack of extensive regeneration might have been due not only to the increased Nogo-B expression, but also to the presence of Mag and Omgp, and this is consistent with redundancy. By contrast, in Strittmatter's gene trap strategy, expression of the Nogo-B isoform was also lost. Also, the regeneration that they observed could have been the result of the gene trap's influence on another gene locus, close to but distinct from the Nogo locus. If so, it might represent a gain-of-function rather than a loss-of-function phenotype. In support of the redundancy hypothesis, Tessier-Lavigne reported that when either Nogo-A and $-\mathrm{B}$, or Nogo-A, $-\mathrm{B}$ and $-\mathrm{C}$, were knocked out, there was no spontaneous regeneration after injury ${ }^{48}$. Clearly, a more detailed examination of the different Nogo-knockout mice will be required before any definitive conclusion can be drawn.

Notwithstanding these conflicting results, if there is redundancy, what are the relative contributions of these three inhibitors to the inhibition of regeneration after injury? Given that Nogo-66, Mag and Omgp all interact with Ngr with about the same relatively high affinity $^{28,32,35,36}$, and assuming that they are the only inhibitors (but see later discussion on amino-Nogo) and that there is only one receptor complex, the contribution that each makes depends on two factors - their relative abundance in myelin, and the likelihood of a growth cone encountering each inhibitor as it attempts to regenerate. Mag represents $1 \%$ and $0.1 \%$ of the total myelin protein in the CNS and PNS, respectively, and it is found mostly in the inner myelin loop in the $\mathrm{CNS}^{23,49}$. Nogo-A has been localized to both the outer and inner myelin membrane in the CNS, although the majority is found in the endoplasmic reticulum, even in the mature nervous system ${ }^{14,28}$. Both Nogo-A and Nogo-B are found in the sciatic nerve, but it is unclear which cells express them ${ }^{14}$. Nogo-A has been reported in one study ${ }^{15}$, but not in another ${ }^{14}$, to be upregulated in the CNS after injury. Omgp is believed to be a relatively minor component of CNS and PNS myelin, with a relative abundance much lower than that of Mag. It has been reported that Omgp is concentrated to paranodal regions ${ }^{50}$. Of these three inhibitors, only Mag seems to be myelin-specific - Nogo-A, -B and Omgp are also expressed by neurons ${ }^{11,29,51}$. It is not known if neuronal/axonal expression of Nogo and Omgp inhibit other axons that are attempting to regenerate. Although a large amount of information has accumulated recently, we cannot definitively claim that one inhibitor is more important in preventing regeneration than another.

The additional inhibitory activity of amino-Nogo (which does not act through Ngr-p75 ${ }^{\text {NTR }}$ ), and perhaps other as yet unidentified myelin inhibitors, must also be considered. The fact that blocking Ngr or $\mathrm{p} 75^{\mathrm{NTR}}$ can substantially block the inhibitory effects of total myelin implies that, at least for the neurons tested so far, this receptor is the most important signalling component for inhibition. However, there might be other receptors on different neurons that interact with the known inhibitors. Indeed, although every older neuron tested to date is inhibited by Mag and myelin ${ }^{18,19}$, some neurons are reported to express little or no p $75^{\text {NTR }}$ in $\operatorname{situ}^{52,53}$. This situation might change after injury, as upregulation of $\mathrm{p} 75^{\text {NTR }}$ has been shown in many axonal tracts $^{5,55}$. The same might hold true for neurons in culture, as their removal and dissociation mimics many aspects of injury. A more thorough characterization of the response of various neuronal subpopulations to myelin inhibitors, and how this correlates with the expression of $\mathrm{p} 75^{\mathrm{NTR}}$ (and Ngr), will be required to answer this question.

In one region of the brain, abnormal growth of axons was reported in mice that overexpressed nerve growth factor (Ngf) and were deficient in $\mathrm{p} 75^{\mathrm{NTR}}$ $\left(\mathrm{Ngf} / \mathrm{p} 75^{\mathrm{NTR}-/-}\right)^{56}$. Overexpression of $\mathrm{Ngf}$ alone causes abnormal sprouting of axons into myelinated tracts in one region of the brain, and this abnormal growth increases markedly in the $\mathrm{Ng} / \mathrm{p} 75^{\mathrm{NTR-1}}$ mice. At present, it is not known if this effect is due to an inability of myelin-associated inhibitors to transduce their signal, or to an enhancement of growth-promoting effects through tyrosine kinase A (TrkA) (the effects in p75 $5^{\text {NTR }}$ deficient mice with normal levels of Ngf were not reported). It is of note that the abnormal growth in $\mathrm{Ng} / \mathrm{p} 75^{\mathrm{NTR}-\mathrm{-}}$ mice was along intact myelin. It is possible that intact myelin, in which few of the known inhibitors are on the surface, is permissive for regeneration, and only when it is disrupted by injury is an abundance of inhibitors exposed to the growth cone. This would seem to be the case when DORSAL ROOT GANGLION (DRG) neurons are transplanted into the mature spinal cord with great care, so that no glial scar forms and myelin is not disrupted ${ }^{57,58}$. In this situation, long processes course through intact white matter. This question could be resolved if it could be shown that spontaneous regeneration occurs after CNS injury in a $\mathrm{p} 75^{\mathrm{NTR}}$ - and/or Ngr-knockout mouse. This would provide unequivocal evidence that the three inhibitory ligands and a single receptor complex are the main players in myelin's ability to prevent axonal regeneration. 


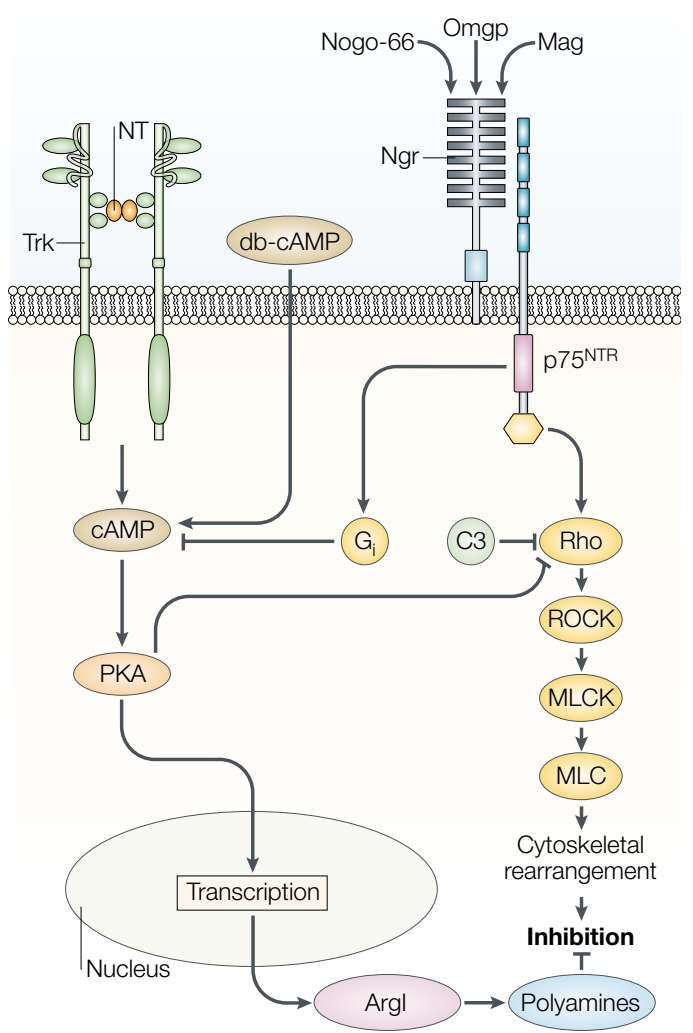

Figure 3 | Model of signalling inhibition through the Ngr-p75 ${ }^{\text {NTR }}$ receptor complex. Activation of Nogo receptor (Ngr)-p75 neurotrophin receptor (p75 NTR) activates Rho, which activates Rho kinase (ROCK), myosin light chain kinase (MLCK) and myosin light chain (MLC) in sequence, resulting in rearrangement of the cytoskeleton and inhibition of axonal growth. Interaction of myelin-associated glycoprotein (Mag) or myelin with the neuron is also believed to activate a $G_{i}$ protein, which is not in the direct signalling pathway for inhibition but inhibits adenylate cyclase, thereby preventing an increase in cyclic AMP (CAMP) when neurons are exposed to neurotrophins and inhibitor at the same time. CAMP can be elevated by either priming with neurotrophins, signalling through tyrosine kinase receptors (Trk), or with nonhydrolysable analogues such as dibutryl cAMP (db-cAMP). cAMP activates protein kinase $A(P K A)$, which can affect inhibition directly, probably by inactivating Rho, but also by triggering transcription of genes such as that for Arginase (Argl), resulting in an increase in synthesis of polyamines that blocks inhibition. C3, Clostridium botulinum C3 exoenzyme; NT, neurotrophin; Omgp, oligodendrocyte myelin glycoprotein.

SMALL GTPASE PROTEINS A family of proteins that can hydrolyse GTP, which includes Rac, Rab, Ran, Rad, Rho and others. They subserve multiple cellular functions; for example, Rho and Rac are involved in the control of the cytoskeleton.

PERTUSSIS TOXIN

The causative agent of whooping cough, pertussis toxin causes the persistent inactivation of $\mathrm{G}$ proteins by catalysing the ADPribosylation of the $\alpha$-subunit.

\section{Signalling by inhibitors of regeneration}

The identification of a receptor complex that interacts with myelin inhibitors confirmed that a specific inhibitory signal is initiated when myelin interacts with neurons/growth cones, rather than following from a general myelin-derived non-permissiveness. Even before the receptor complex was known, members of the Rho family of SMALL GTPASE PROTEINS had been implicated in myelin's inhibitory effects ${ }^{59}$ (FIG. 3). This is not surprising, as these proteins had been established as key regulators of the actin cytoskeleton in fibroblasts ${ }^{60}$, and any signalling cascade that has an effect on growth cone, and so axonal, dynamics must ultimately effect changes in the cytoskeleton.
In cultured neurons, inactivation of Rho has been shown by several groups to overcome inhibition by individual inhibitors and by myelin in general ${ }^{59,61-64}$. Rho has also been reported to be constitutively associated with $\mathrm{p} 75^{\mathrm{NTR}}$, and this direct interaction causes Rho to remain active. Binding of Ngf to $\mathrm{p} 75^{\mathrm{NTR}}$ induces dissociation and consequently inactivation of Rho. By contrast, it has also been reported that Rho only associates with $\mathrm{p} 75^{\mathrm{NTR}}$ and becomes active on binding of Mag to the receptor complex ${ }^{37}$. More recently, it was reported that $\mathrm{p} 75^{\mathrm{NTR}}$ interacts only indirectly with Rho by binding to and displacing Rho-GDP dissociation inhibitor (Rho-GDI), thereby activating $\mathrm{Rho}^{65}$.

Regardless of the mechanism of activation, Rho undoubtedly has a key role in signalling by myelin inhibitors in vivo. Inactivation of Rho by application of the toxin $\mathrm{C} 3$ to the site of spinal cord injury results in extensive regeneration and functional recovery in mice ${ }^{66}$. In these $\mathrm{C} 3$-treated mice, however, there was a marked improvement in function two days post-injury, too soon to be accounted for by axonal regeneration. Instead, it is proposed that these early effects could be a consequence of an early effect of C3 on neuron survival, a suggestion that remains to be confirmed. Of the six downstream effectors of Rho that have been identified to date, only Rho kinase (ROCK) has been implicated in regeneration; inhibition of ROCK overcomes inhibition by Mag, Nogo and myelin in general ${ }^{62,66}$.

Another member of the Rho family of kinases, Rac, has been implicated in myelin-inhibitor signalling pathways ${ }^{63}$. As well as activating Rho, inhibitors in myelin inactivate Rac. It remains to be shown whether inactivation of Rac is required for inhibition to occur and, conversely, whether activation of Rac is sufficient to block inhibition.

Several years ago, one report indicated that the heterotrimeric G-proteins have a role in inhibition. It was shown that inhibition of $\mathrm{G}_{\mathrm{i}} / \mathrm{G}_{\mathrm{o}}$ with PERTUssis TOXIN blocked myelin-induced growth cone collapse ${ }^{67}$. We, on the other hand, reported that pertussis toxin had no effect on inhibition by Mag and myelin ${ }^{68}$. This discrepancy in results can perhaps be explained by differences in the acute dynamics of growth cone collapse and the chronic dynamics of the cessation of growth that are required for inhibition (BOX 3).

As with most signalling cascades that ultimately influence the behaviour of the cytoskeleton, calcium is probably involved. Myelin has been shown to induce calcium influx into neurons, and growth cone collapse by Mag, Nogo and oligodendrocytes in culture is calcium-dependent ${ }^{42,69}$. Where calcium acts in the signalling pathway, and whether it is released from internal stores or from the exterior, has yet to be determined.

To date, the strongest evidence for an involvement in signalling by myelin inhibitors rests with the studies on Rho ${ }^{62,63,66}$. As stated above, Rho has been suggested to interact directly with p $75^{\mathrm{NTR}}$ (REF 37). As activation of $\mathrm{p} 75^{\mathrm{NTR}}$ has also been reported to initiate several signalling cascades $^{70}$, it is possible that some of these same pathways are activated when myelin inhibitors bind to the Ngr-p $75^{\text {NTR }}$ receptor complex. These signalling cascades 
Growth cone collapse is probably the first event in inhibition, and many of the treatments that overcome inhibition of axonal growth also block growth cone collapse/repulsion ${ }^{68,74}$. Mechanistically, collapse and turning are the same, all that differs is the amount of growth cone that is exposed to inhibitors. For growth cone collapse, exposure is uniform, so the entire growth cone responds. For repulsion, only one side of the growth cone encounters the inhibitor, so there is an asymmetric response, leading to a turn. However, there are differences in the dynamics of collapse/repulsion and the slowing or complete cessation of growth that is required for inhibition. The former is acute (occurring within minutes) and highly dynamic, whereas the latter is chronic (occurring over hours or days).

Although there are many similarities in the molecular events that bring about collapse and inhibition, and so similarities in treatments that block them, the differences in their dynamics imply that there are important differences between them. This has been supported by the fact that growth cones of young neurons that are not inhibited by myelinassociated glycoprotein (Mag) and myelin collapse when they encounter oligodendrocytes. Unlike their older counterparts, which are inhibited by Mag and myelin, these young growth cones recover rapidly and go on to grow ${ }^{108}$.

These differences are also likely to characterize how cyclic AMP (cAMP) overcomes collapse/repulsion and inhibition. Elevated cAMP in neurons overcomes inhibition in two phases. The first phase is rapid, directly dependent on protein kinase A (PKA) activation and transcription-independent. The mechanism involved in this phase is probably the same mechanism that overcomes collapse/repulsion. In the second phase, the ability to overcome inhibition becomes PKAindependent but transcription-dependent ${ }^{76,77}$. It is likely that cAMP initiates two events. First, it activates PKA, which might have a direct effect on the dynamics of the cytoskeleton without involving new transcription. Through the simultaneously activated but slower pathway, it also eventually leads to transcription and synthesis of proteins, which in turn allows the axon to grow through inhibitors. Once transcription has been initiated, the programme is independent of cAMP/PKA. This apparent difference in mechanism is important when considering potential therapies to overcome inhibition in vivo. The demonstration that an agent reverses collapse or repulsion might not be sufficient to ensure that it overcomes the more chronic state of inhibition.

could then run in parallel with the Rho pathway to bring about inhibition. This needs to be investigated further, as the more information we have on inhibitory molecule signalling, the more potential therapeutic targets are revealed.

Overcoming inhibitors of regeneration in myelin There are two general approaches that could be used to overcome inhibitors and encourage regeneration - to block the inhibitors and/or their receptor(s) with antibodies and/or peptides, or to change the intrinsic state of the neuron such that it no longer recognizes the environment as inhibitory.

Blocking the inhibitors and receptors. The IN-1 antibody has been used in different models of regeneration, with varying degrees of success, for more than a decade ${ }^{10,43,44}$. However, the recent explosion in our knowledge of other components of the receptor-ligand complex that causes inhibition has greatly increased the number of possible targets for therapeutic intervention using peptides or antibodies.

The common receptor complex for the three known myelin inhibitors immediately emerges as an attractive target. Inhibiting the function of this complex would presumably block the three inhibitors simultaneously. Two approaches are possible: to block the interaction of the inhibitors with Ngr or to block the interaction of Ngr with $\mathrm{p} 75^{\mathrm{NTR}}$. The success of the former approach will depend on whether the binding sites for the three inhibitors on Ngr are distinct or overlapping. The ligand binding region for all three inhibitors has already been shown to require the first eight LRRs of Ngr, but not the LLRCT region $^{45,71}$, whereas both of these regions are needed for interaction with $\mathrm{p} 75^{\mathrm{NTR}}$ and inhibition ${ }^{38}$. Recently, a 40-amino-acid peptide corresponding to a
Nogo-66 sequence was shown to bind to the LRR ligand binding site on Ngr without exerting inhibition ${ }^{45}$. This peptide blocked inhibition by myelin in culture, and when it was applied in vivo it resulted in improved regeneration and an improvement of functional recovery in a model of spinal cord injury. The authors argue that this peptide is specific for Nogo-66 interaction with Ngr and does not affect Mag or Omgp binding. They conclude, therefore, that Nogo-66 is the main inhibitor, because when only Nogo-66 is blocked does considerable regeneration occur. By contrast, we showed that Mag could compete with Nogo-66 for binding to $\mathrm{Ngr}^{36}$.

Attempts to prevent receptor-mediated signal transduction by blocking the interaction between Ngr and p $75^{\text {NTR }}$ have not yet been reported. The C-terminal LRRCT of Ngr is responsible for interaction with $\mathrm{p} 75^{\mathrm{NTR}}$ (REF 45), a view that is supported by the characteristics of the receptor that were obtained from the crystal structure ${ }^{40}$. These sequences would be the obvious place to start in the development of agents to block the transduction step and encourage regeneration in vivo.

Changing the intrinsic state of the neuron. A second approach to overcoming inhibition is to change the neuron intrinsically so that it does not respond to inhibitors. Several different groups have risen to this challenge, and inactivation of Rho has resulted in the greatest success in terms of regeneration in vivo. The targeted use of the Rho inhibitor C3 allows the effects to be confined largely to the lesioned spinal cord, thereby avoiding possible deleterious effects of widespread inactivation.

C3 is largely membrane impermeable, and once applied locally to the lesioned CNS, it cannot readily diffuse to other tissues ${ }^{66}$. Indeed, when $\mathrm{C} 3$ is delivered intrathecally, it has no effect on regeneration in vivo, whereas delivery of Y27632, an inhibitor of ROCK, 


\section{POLYAMINES}

Organic compounds that contain two or more amino groups. Putrescine, spermine and spermidine are prime examples.

INWARDLY RECTIFYING K+ CHANNELS

Potassium channels that allow long depolarizing responses, as they close during depolarizing pulses and open with steep voltage dependence on hyperpolarization. They are called inward rectifiers because current flows through them more easily into than out of the cell. results in regeneration ${ }^{62}$. It remains to be seen whether the effects of the new generation of C3 molecules, which are more membrane-permeable, can be similarly confined and effective ${ }^{72}$

The success with Rho was initially explained by the belief that its signalling represented a convergence in signalling by all myelin inhibitors interacting with different receptors. However, it is now clear that the common convergence point for the inhibitors is actually the Ngr, which in turn activates Rho (the exception is aminoNogo, which also activates Rho, but not through Ngr-p $75^{\text {NTR }}$ REF. 73)

Instead of manipulating the direct inhibitory signalling pathway, it is possible to activate parallel signalling pathways to overcome inhibition by myelin. For example, elevation of cyclic AMP (cAMP) overcomes inhibition by Mag and myelin ${ }^{68,73}$. Similarly, when either soluble Mag or myelin is presented to the growth cone in an asymmetric gradient, elevation of cAMP changes repulsion to attraction ${ }^{74}$ (BOX 3). cAMP can be elevated in several different ways - artificially with membranepermeable analogues, with forskolin (which activates adenylyl cyclase), with phosphodiesterase inhibitors (which block cAMP degradation) or, surprisingly, with various neurotrophins ${ }^{68}$ (FIG. 3).

Neurotrophins only elevate cAMP if they are presented to the neuron in the absence of myelin inhibitors. Therefore, for neurotrophins to overcome inhibition by myelin, neurons must be 'primed' with the neurotrophin of choice before being exposed to the inhibitor. However, if neurotrophins are added directly to the neurons but in the presence of the $G_{i} / G_{0}$ inhibitor pertussis toxin, inhibition is blocked without priming. The working model is that although blocking $G_{i} / G_{0}$ has no direct effect on inhibition by Mag or myelin, Mag and myelin activate $G_{i} / G_{o}$, which then blocks the adenylyl cyclase-dependent, neurotrophin-induced increase in cAMP. Indeed, all the mechanisms of elevating cAMP (apart from the analogues, which are completely independent of adenylyl cyclase activity) are more effective if neurons are primed with the reagent before they encounter the inhibitor. In vivo, DRG axons that had been crushed between the cell body and the dorsal root entry zone (DREZ) grew into the spinal cord when they were treated with neurotrophins ${ }^{75}$. Usually, these axons stop abruptly when they encounter CNS tissue at the DREZ, but here they are exposed to neurotrophin while they are growing towards the spinal cord, so they are effectively being primed with neurotrophin before they reach the DREZ. What is particularly interesting is that these regenerating axons first grow through reactive astrocytes that migrate into the nerve root. Once past the DREZ, the axons encounter white and grey matter. Priming with neurotrophins might not only overcome inhibitors in myelin, but also inhibitors in the glial scar. It is notable that the ability to overcome inhibition by priming with neurotrophins is effected through Trk receptors (Y. Gao and M.F., unpublished observations), and inhibition of growth by myelin-associated inhibitors is exerted through p $75^{\text {NTR }}$ (REFS 38,39), even though there seems to be no crosstalk between these two events.
What are the downstream consequences of cAMP signalling that overcome inhibition? There seem to be two phases to the cAMP effect ${ }^{76}$. In the first phase, protein kinase A (PKA) is activated, and this could have a direct effect on the cytoskeleton, possibly by inactivating Rho. This phase of the cAMP effect is acute and transcription-independent, so it probably accounts for the immediate effects on growth cone turning or collapse (BOX 3). In the second phase, both the effect of cAMP analogues, such as dibutryl cAMP (db-cAMP), and the effects of brain-derived neurotrophic factor (BDNF) become transcription-dependent ${ }^{77}$. This transcription is initiated by a transient increase in cAMP and PKA activation, but it then switches to a PKA-independent mechanism ${ }^{76}$. One gene that has been shown to be upregulated in response to elevation of cAMP is the gene that codes for Arginase I ( $A r g I)$, a key enzyme in the synthesis of POLYAMINES ${ }^{77}$. Many older studies had implicated polyamines in regeneration, but none showed a definitive effect on overcoming myelin inhibitors ${ }^{78-80}$. We have shown that either overexpression of ArgI or exogenous addition of polyamines, is sufficient to overcome inhibition by Mag and myelin. Conversely, blocking either ArgI or the next enzyme in polyamine synthesis - ornithine decarboxylase (Odc) - can abrogate the ability of db-cAMP or BDNF to overcome inhibition.

A plethora of effects of polyamines on numerous aspects of cell behaviour have been described. Polyamines have been shown to influence the cytoskeleton directly $^{81-83}$, block INWARDLY RECTIFYING POTASSIUM CHANNELS ${ }^{84}$, block calcium-permeable glutamate receptor channels ${ }^{85-87}$, and to influence chromatin structure and, consequently, transcription ${ }^{88}$. Polyamines might exert their effects on inhibition through one or a combination of these functions. Regulation of polyamine synthesis by neuronal activity has recently been described as a new form of modulation of synaptic transmission, which in turn has been implicated in several neuronal processes that require process/sprout formation, such as circuit formation during development, memory and learning ${ }^{89}$. Interestingly, electrical activity has been shown to reverse the effect of Mag and myelin on growth cone turning from repulsion to attraction, in a cAMPdependent manner ${ }^{90}$. The question of whether these two events are triggered by the same molecular interactions remains unanswered. Although not straightforward and unlikely to be completely dependent on any one effect of polyamines, it is important to characterize these effects with the goal of identifying more specific therapeutic targets for intervention after injury, rather than relying on the global effects of elevating cAMP.

\section{Insight from systems that regenerate in vivo}

One starting point for identifying genes/proteins that are required for regeneration is to look for genes that are upregulated or expressed at high levels in systems that regenerate spontaneously after injury. Most studies have focused on two situations in which this occurs - neonatal spinal neurons, which often regenerate to produce complete functional recovery ${ }^{91,92}$, and regeneration of the 


\begin{tabular}{lllll}
\multicolumn{6}{l}{ Table 2 | Comparison of treatments that overcome inhibition } \\
Condition/Treatment & cAMP & Argl & Polyamines & Regeneration in vivo \\
BDNF & ++ & ++ & ++ & + \\
Young neurons & ++ & ++ & $\mathrm{ND}$ & ++++ \\
db-cAMP & $\mathrm{NA}$ & ++ & ++ & +++ \\
Conditioning lesion (1 day) & +++ & - & - & + \\
Conditioning lesion (7 days) & - & +++ & +++ & +++ \\
\hline
\end{tabular}

Argl, Arginase I; BDNF, brain derived neurotrophic factor; cAMP, cyclic AMP, NA, not apllicable; ND, no data. + indicates expression or regeneration relative to untreated/unlesioned.

CNS branch of DRG neurons (dorsal column axons) after the peripheral branch of the same neuron has previously been lesioned ${ }^{93,94}$. In the latter case, if only the dorsal column is lesioned, there is no spontaneous re-growth, as with all other mature CNS axons.

In both situations, spontaneous regeneration could be due to the creation of a more favourable environment for regeneration and/or changes in the intrinsic state of the neuron. In the case of young neurons, both factors

\section{Conditioning lesion}

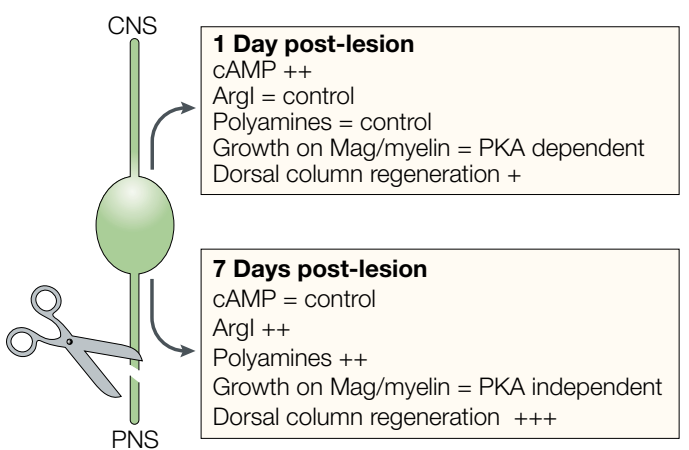

db-cAMP injection

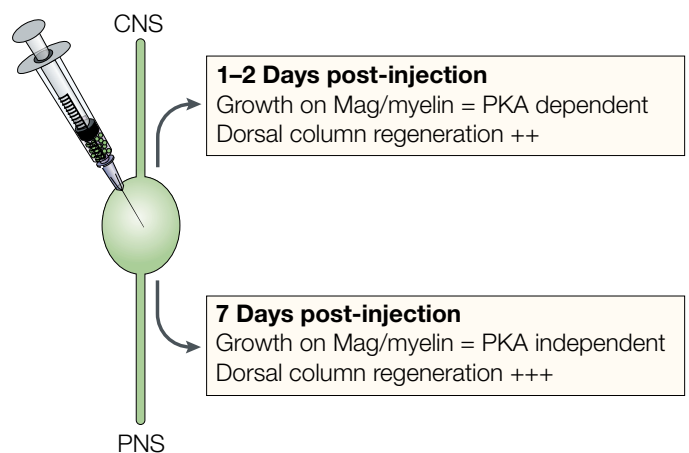

Figure 4 | Elevation of cyclic AMP mimics the effects of a peripheral conditioning lesion on dorsal column regeneration. For the conditioning lesion, the peripheral branch of the dorsal root ganglion is lesioned 1,2 or 7 days before carrying out the assays/measurements as described. To elevate cAMP, dibutryl cAMP (db-cAMP) was injected directly into the dorsal root ganglion cell bodies in the absence of a peripheral lesion, and the animals were left for 1,2 or 7 days before carrying out the assays/measurements as described in the text. Argl, Arginase I; CNS, central nervous system; Mag, myelin-associated glycoprotein; PKA, protein kinase A; PNS, peripheral nervous system. + indicates expression or regeneration relative to untreated/unlesioned. seem to have a role. The environment certainly changes with development, as more myelin is laid down. However, the response of these young neurons to that environment also changes. Young neurons are not inhibited by Mag or myelin ${ }^{18}$, and will spontaneously regenerate, whereas older neurons are inhibited by Mag and myelin, and will not regenerate after injury ${ }^{17,91,92}$. On the other hand, the effects of a conditioning lesion are probably due entirely to changes in the intrinsic state of the neuron, such that it no longer recognizes myelin as inhibitory.

In various young neurons, at an age when they are not inhibited by Mag or myelin in general and can spontaneously regenerate, cAMP levels are high ${ }^{18}$. cAMP levels drop spontaneously and precipitously with development at a time that correlates with their loss of regenerative ability and the appearance of an inhibitory response to Mag and myelin. Furthermore, in at least one population of young neurons, the level of expression of ArgI parallels that of cAMP, with a decline in ArgI expression occurring sharply when these neurons lose their ability to grow on Mag and myelin. Importantly, preventing polyamine synthesis by blocking either ArgI or Odc in these young neurons blocks their ability to grow on Mag and myelin. It is of note that these young neurons express both Ngr and $\mathrm{p} 75^{\mathrm{NTR}}$, so they should be able to respond to myelin inhibitors (M. Domeniconi and M.F., unpublished observations). This indicates that the signalling that is exerted by this receptor complex might be different for old and young neurons. Moreover, most young neurons are not merely unresponsive to Mag; rather, neurite outgrowth is actually promoted ${ }^{17,21,95}$. It remains to be shown whether the Ngr-p $75^{\mathrm{NTR}}$ receptor complex is used for this promoting effect. If so, the cAMP/ArgI levels could determine their response (TABLE 2).

The ability of a conditioning peripheral lesion to elicit regeneration of central dorsal column axons has long been recognized. The first studies described improved growth after a conditioning lesion of dorsal column axons into a peripheral nerve graft ${ }^{94}$. However, it was only recently that a conditioning lesion was shown to induce regeneration of dorsal column axons in the absence of a peripheral nerve graft ${ }^{93}$. cAMP also seems to have an important role in this phenomenon ${ }^{76,96}$. Twenty-four hours after a peripheral conditioning lesion, cAMP levels in DRGs have more than doubled, but by one week after the lesion, they are back to uninjured control levels. Consistent with this, if DRGs are removed one day postlesion and cultured on myelin, they are not inhibited, and their improved growth can be blocked by an inhibitor of PKA. By one week post-lesion, the DRGs grow even better on myelin, but this growth is now PKA-independent (FIG. 4). Furthermore, the improved growth that is produced by a peripheral lesion switches from being transcription-dependent to transcription-independent, mimicking the response of neurons treated with db-cAMP in culture, although on a different timescale.

Of particular importance is the fact that injection of db-cAMP directly into the DRG cell body 1, 2 or 7 days before the DRGs are removed, or before the dorsal 
columns are lesioned, mimics the effects of a conditioning lesion on both neurons grown in culture and on dorsal column axons in $v i v o^{76,96}$ (FIG. 4). This observation is important for two reasons; first, it shows that treatment of the cell body can affect the growth of axons some distance away, and second, it indicates that elevation of cAMP is sufficient to reproduce the effects of a conditioning lesion. Furthermore, after a conditioning lesion, there is also an increase in expression of ArgI, beginning at about 30 hours post-lesion, peaking at 40 hours and remaining high for at least 8 days (J. Qiu and M.F., unpublished observations) (TABLE2).

Another protein that has been shown to be upregulated after a conditioning lesion is a small proline-rich repeat protein called Sprrpla, which associates with F-actin in the growth cone ${ }^{97}$. This protein is not expressed during development; its expression is only associated with axons that regenerate. When it is overexpressed, Sprrpla can promote general neurite outgrowth, but it does not overcome inhibitors in myelin. Similarly, growth-associated protein 43 (Gap43), which has long been associated with regenerating axons, can also promote neurite outgrowth, but not through an inhibitory environment ${ }^{98,99}$. In transgenic mice that overexpress Gap43, together with a similar protein Cap23, lesioned dorsal column axons will spontaneously regenerate into a peripheral nerve graft in the absence of a peripheral conditioning lesion ${ }^{100}$. However, the ability of these neurons to grow on an inhibitory substrate was not addressed. Both of these studies illustrate the fact that it is not sufficient to merely promote growth on a permissive substrate - for successful regeneration to occur, any treatment must render the neuron/axon capable of overcoming inhibitors.

\section{Future perspectives}

Although significant advances have been made recently in identifying the molecular players that are involved in myelin inhibition of axonal regeneration, the story is far from complete. The observation that the main inhibitors function through the same receptor and signalling cascade is encouraging, because it indicates that it should be relatively easy to block all three inhibitors simultaneously. However, in addition to amino-Nogo, it is likely that other inhibitors, receptors and signalling pathways are activated when myelin interacts with an axon that is attempting regeneration.

In terms of functional recovery, overcoming inhibitors of regeneration in myelin is only one aspect of a complex problem. Even if axons can be induced to grow across the lesion site before the glial scar forms, they still need to be directed back to their correct destination, and make functional synapses once they have arrived. The first step, of course, is to get the axons to grow, and in the last few years, enormous advances have been made in this respect.
1. Fitch, M. T. \& Silver, J. in CNS Regeneration (eds Tuszynski, M. H. \& Kordower, J. H.) 55-88 (Academic, San Diego, 1999).

2. Qiu, J., Cai, D. \& Filbin, M. T. Glial inhibition of nerve regeneration in the mature mammalian CNS. Glia 29 , 166-174 (2000).

3. Schwab, M. E. \& Bartholdi, D. Degeneration and regeneration of axons in the lesioned spinal cord. Physiol. regeneration of axons in

4. Huang, D. W., McKerracher, L., Braun, P. E. \& David, S. A therapeutic vaccine approach to stimulate axon regeneration in the adult mammalian spinal cord. Neuron 24, 639-647 (1999).

5. Ramón y Cajal, S. Cajal's Degeneration \& Regeneration of the Nervous System (eds DeFelipe, J. \& Jones, E. G.) (Oxford Univ. Press, Oxford, 1928).

6. Berry, M. Post-injury myelin-breakdown products inhibit axonal growth: an hypothesis to explain the failure of axon axonat gron in the mammalian central nenous system $B$ ib Anat. 23, 1-11 (1982).

\section{The first experimental data that support the} suggestion that myelin inhibits axonal regeneration.

7. Crutcher, K. A. Tissue sections from the mature rat brain and spinal cord as substrates for neurite outgrowth in vitro: extensive growth on gray matter but little growth on white matter. Exp. Neurol. 104, 39-54 (1989).

8. Caroni, P. \& Schwab, M. E. Two membrane protein fractions from rat central myelin with inhibitory properties for neurite growth and fibroblast spreading. J. Cell Biol. 106, 1281-1288 (1988)

9. Caroni, P. \& Schwab, M. E. Antibody against myelinassociated inhibitor of neurite growth neutralizes nonpermissive substrate properties of CNS white matter. nonpermissive substrate p
Neuron 1, 85-96 (1988). Neuron 1, 85-96 (1988).
References 8 and 9 identify inhibitory fractions in References 8 and 9 identify inhibitory fractions in
myelin and describe the IN-1 monoclonal antibody that neutralizes the inhibition.

10. Schnell, L. \& Schwab, M. E. Axonal regeneration in the rat spinal cord produced by an antibody against myelin-associated neurite growth inhibitors. Nature 343, 269-272 (1990).

11. Chen, M. S. et al. Nogo-A is a myelin-associated neurite outgrowth inhibitor and an antigen for monoclonal antibody IN-1. Nature 403, 434-439 (2000).

12. GrandPre, T., Nakamura, F., Vartanian, T. \& Strittmatter, S. M. Identification of the Nogo inhibitor of axon regeneration as a Reticulon protein. Nature 403, 439-444 (2000).
13. Priniha, R. et al. Inhibitor of neurite outgrowth in humans Nature 403, 383-384 (2000). References 11-13 describe the cloning of Nogo, a long-sought antigen of the $\mathbf{I N - 1}$ monoclonal antibody.

14. Huber, A. B., Weinmann, O., Brosamle, C., Oertle, T. \& Schwab. M. E Patterns of Nogo mRNA and protein expression in the developing and adult rat and after CNS lesions. J. Neurosci. 22, 3553-3567 (2002).

15. Wang, X. et al. Localization of Nogo-A and Nogo-66 receptor proteins at sites of axon-myelin and synaptic contact. J. Neurosci. 22, 5505-15 (2002).

16. McKerracher, L. et al. Identification of myelin-associated glycoprotein as a major myelin-derived inhibitor of neurite growth. Neuron 13, 805-811 (1994)

17. Mukhopadhyay, G., Doherty, P., Walsh, F. S., Crocker, P. R. \& Filbin, M. T. A novel role for myelin-associated glycoprotein as an inhibitor of axonal regeneration. Neuron 13, 757-767 (1994).

18. Cai, D. et al. Neuronal cyclic amp controls the developmental loss in ability of axons to regenerate. J. Neurosci. 21 4731-4739 (2001).

19. de Bellard, M. \& Filbin, M. T. Myelin-associated glycoprotein MAG, selectively binds several neuronal proteins. J. Neurosci. Res. 56, 213-218 (1999).

20. Turnley, A. M. \& Bartlett, P. F. MAG and MOG enhance neurite outgrowth of embryonic mouse spinal cord neurons. Neuroreport 9, 1987-1990 (1998).

21. Johnson, P. W. et al. Recombinant myelin-associated glycoprotein confers neural adhesion and neurite outgrowth function. Neuron $\mathbf{3}, 377-385$ (1989).

22. Salzer, J. L., Holmes, W. P. \& Colman, D. R. The amino acid sequences of the myelin-associated glycoproteins: homology to the immunoglobulin gene superfamily. J. Cell Biol. 104, 957-965 (1987).

23. Salzer, J. L. et al. Structure and function of the myelinassociated glycoproteins. Ann. NY Acad. Sci. 605, 302-312 (1990).

24. Kelm, S. et al. Sialoadhesin, myelin-associated glycoprotein and CD22 define a new family of sialic acid-dependent adhesion molecules of the immunoglobulin superfamily. Curr. Biol. 4, 965-972 (1994).

25. Tang, S. et al. Myelin-associated glycoprotein interacts with neurons via a sialic acid binding site at ARG118 and a distinct neurite inhibition site. J. Cell Biol. 138, 1355-1366 (1997).
26. Trapp, B. D. Distribution of the myelin-associated glycoprotein and P0 protein during myelin compaction in quaking mouse peripheral nerve. J. Cell Biol. 107, 675-685 (1988).

27. Willison, H. J. et al. Myelin-associated glycoprotein and related glycoconjugates in developing cat peripheral nerve: a correlative biochemical and morphometric study. a correlative biochemical and morphom

28. Wang, K. C. et al. Oligodendrocyte-myelin glycoprotein is a Nogo receptor ligand that inhibits neurite outgrowth. Nature 417, 941-944 (2002)

29. Habib, A. A. et al. Expression of the oligodendrocyte-myelin glycoprotein by neurons in the mouse central nervous system. J. Neurochem. 70, 1704-1711 (1998).

30. Mikol, D. D., Gulcher, J. R. \& Stefansson, K. The oligodendrocyte-myelin glycoprotein belongs to a distinct family of proteins and contains the HNK-1 carbohydrate. J. Cell Biol. 110, 471-479 (1990).

31. Kottis, V. et al. Oligodendrocyte-myelin glycoprotein (OMgp) is an inhibitor of neurite outgrowth. J. Neurochem. $\mathbf{8 2}$ 1566-1569 (2002).

32. Fournier, A. E., GrandPre, T. \& Strittmatter, S. M. Identification of a receptor mediating Nogo-66 inhibition of axonal regeneration. Nature 409, 341-346 (2001). Identifies the first receptor for an inhibitor found in myelin.

33. Josephson, A. et al. Nogo-receptor gene activity: cellular localization and developmental regulation of $\mathrm{mRNA}$ in mice and humans. J. Comp. Neurol. 453, 292-304 (2002).

34. Oertle, T. et al. Nogo-A inhibits neurite outgrowth and cell spreading with three discrete regions. J. Neurosci. $\mathbf{2 3}$ 5393-5406 (2003).

35. Liu, B. P., Fournier, A., GrandPre, T. \& Strittmatter, S. M. Myelin-associated glycoprotein as a functional ligand for the Nogo-66 receptor. Science 297, 1190-1193 (2002).

36. Domeniconi, M. et al. Myelin-associated glycoprotein interacts with the Nogo66 receptor to inhibit neurite outgrowth. Neuron 35, 283-290 (2002). References $\mathbf{3 5}$ and $\mathbf{3 6}$ reveal, surprisingly, that Mag interacts with the $\mathrm{Ngr}$, and reference 34 shows that OMgp also interacts with this receptor.

37. Yamashita, T., Higuchi, H. \& Tohyama, M. The p75 receptor transduces the signal from myelin-associated glycoprotein to Rho. J. Cell Biol. 157, 565-570 (2002). 
38. Wang, K. C., Kim, J. A., Sivasankaran, R., Segal, R. \& He, Z P75 interacts with the Nogo receptor as a co-receptor for Nogo, MAG and OMgp. Nature 420, 74-78 (2002).

39. Wong, S. T. et al. A p75 ${ }^{\text {NTR }}$ and Nogo receptor complex mediates repulsive signaling by myelin-associated glycoprotein. Nature Neurosci. 5, 1302-1308 (2002). References 37-39 identify the $\mathrm{p} 75^{\mathrm{NTR}}$ as a transducing partner of $\mathrm{Ngr}$

40. He, X. L. et al. Structure of the Nogo receptor ectodomain. A recognition module implicated in myelin inhibition. Neuron 38, 177-185 (2003)

41. Bartsch, U. et al. Lack of evidence that myelin-associated glycoprotein is a major inhibitor of axonal regeneration in the CNS. Neuron 15, 1375-1381 (1995).

42. Li, M. et al. Myelin-associated glycoprotein inhibits neurite/axon growth and causes growth cone collapse. J. Neurosci. Res. 46, 404-414 (1996).

43. Bregman, B. S. et al. Recovery from spinal cord injury mediated by antibodies to neurite growth inhibitors. Nature 378, 498-501 (1995)

44. Schnell, L. \& Schwab, M. E. Sprouting and regeneration of lesioned corticospinal tract fibres in the adult rat spinal cord. Eur. J. Neurosci. 5, 1156-1171 (1993).

45. GrandPre, T., Li, S. \& Strittmatter, S. M. Nogo-66 receptor antagonist peptide promotes axonal regeneration. Nature 417, 547-551 (2002).

46. Kim, J. E., Li, S., GrandPre, T., Qiu, D. \& Strittmatter, S. M. Axon regeneration in young adult mice lacking nogo-a/b. Neuron 38, 187-199 (2003).

47. Simonen, M. et al. Systemic deletion of the myelinassociated outgrowth inhibitor Nogo-A improves regenerative and plastic responses after spinal cord injury. Neuron 38, 201-211 (2003).

48. Zheng, B. et al. Lack of enhanced spinal regeneration in Nogo-deficient mice. Neuron 38, 213-224 (2003).

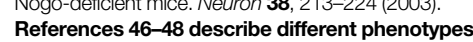

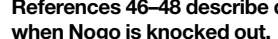

49. Trapp, B. D. Myelin-associated glycoprotein. Location and potential functions. Ann. NY Acad. Sci. 605, 29-43 (1990).

50. Apostolski, S. et al. Identification of Gal( $(\beta 1-3)$ GalNAc bearing glycoproteins at the nodes of Ranvier in peripheral nerve. J. Neurosci. Res. 38, 134-141 (1994).

51. Josephson, A., Widenfalk, J., Widmer, H. W., Olson, L. \& Spenger, C. NOGO mRNA expression in adult and fetal human and rat nervous tissue and in weight drop injury. Exp. Neurol. 169, 319-328 (2001).

52. McMahon, S. B., Armanini, M. P., Ling, L. H. \& Phillips, H. S. Expression and coexpression of Trk receptors in subpopulations of adult primary sensory neurons projecting to identified peripheral targets. Neuron 12, 1161-1171 (1994)

53. Wright, D. E. \& Snider, W. D. Neurotrophin receptor mRNA expression defines distinct populations of neurons in rat dorsal root ganglia. J. Comp. Neurol. 351, 329-338 (1995)

54. Ernfors, P., Henschen, A., Olson, L. \& Persson, $\mathrm{H}$. Expression of nerve growth factor receptor mRNA is developmentally regulated and increased after axotomy in rat spinal cord motoneurons. Neuron 2, 1605-1613 (1989)

55. Koliatsos, V. E., Crawford, T. O. \& Price, D. L. Axotomy induces nerve growth factor receptor immunoreactivity in spinal motor neurons. Brain Res. 549, 297-304 (1991).

56. Walsh, G. S., Krol, K. M., Crutcher, K. A. \& Kawaja, M. D. Enhanced neurotrophin-induced axon growth in myelinated portions of the CNS in mice lacking the p75 neurotrophin receptor. J. Neurosci. 19, 4155-4168 (1999).

57. Davies, S. J. et al. Regeneration of adult axons in white matter tracts of the central nervous system. Nature $\mathbf{3 9 0}$ 680-683 (1997).

58. Davies, S. J., Goucher, D. R., Doller, C. \& Silver, J. Robust regeneration of adult sensory axons in degenerating white matter of the adult rat spinal cord. J. Neurosci. 19 5810-5822 (1999).

59. Lehmann, M. et al. Inactivation of Rho signaling pathway promotes CNS axon regeneration. J. Neurosci. 19 7537-7547 (1999).

60. Hall, A. Rho GTPases and the actin cytoskeleton. Science 279, 509-514 (1998)

61. Jin, Z. \& Strittmatter, S. M. Rac1 mediates collapsin-1induced growth cone collapse. J. Neurosci. 17, 6256-6263 (1997)

62. Fournier, A. E., Takizawa, B. T. \& Strittmatter, S. M. Rho kinase inhibition enhances axonal regeneration in the injured CNS.J. Neurosci. 23, 1416-1423 (2003).

63. Niederost, B., Oertle, T., Fritsche, J., McKinney, R. A. \& Bandtlow, C. E. Nogo-A and myelin-associated glycoprotein mediate neurite growth inhibition by antagonistic regulation of RhoA and Rac1. J. Neurosci. 22, 10368-10376 (2002).
64. Vinson, M. et al. Myelin-associated glycoprotein interacts with ganglioside GT1b. A mechanism for neurite outgrowth inhibition. J. Biol. Chem. 276, 20280-20285 (2001).

65. Yamashita, T. \& Tohyama, M. The $\mathrm{p} 75$ receptor acts as a displacement factor that releases Rho from Rho-GDI. Nature Neurosci. 6, 461-467 (2003).

66. Dergham, P. et al. Rho signaling pathway targeted to promote spinal cord repair. J. Neurosci. 22, 6570-6577 (2002).

67. Igarashi, M., Strittmatter, S. M., Vartanian, T. \& Fishman, M. C. Mediation by $G$ proteins of signals that cause collapse of growth cones. Science 259, 77-79 (1993).

68. Cai, D., Shen, Y., de Bellard, M., Tang, S. \& Filbin, M. T. Prior exposure to neurotrophins blocks inhibition of axonal regeneration by MAG and myelin via a cAMP-dependent mechanism. Neuron 22, 89-101 (1999).

69. Bandtlow, C. E., Schmidt, M. F., Hassinger, T. D., Schwab, M. E. \& Kater, S. B. Role of intracellular calcium in NI-35evoked collapse of neuronal growth cones. Science $\mathbf{2 5 9}$ 80-83 (1993).

70. Hempstead, B. L. The many faces of $\mathrm{p} 75^{\mathrm{NTR}}$. Curr. Opin. Neurobiol. 12, 260-267 (2002).

71. Fournier, A. E., Gould, G. C., Liu, B. P. \& Strittmatter, S. M. Truncated soluble Nogo receptor binds Nogo-66 and blocks inhibition of axon growth by myelin. J. Neurosci. 22 8876-8883 (2002).

72. Winton, M. J., Dubreuil, C. I., Lasko, D., Leclerc, N. \& McKerracher, L. Characterization of new cell permeable C3like proteins that inactivate Rho and stimulate neurite outgrowth on inhibitory substrates. J. Biol. Chem. 277, 32820-32829 (2002)

73. Bandtlow, C. E. Regeneration in the central nervous system. Exp. Gerontol. 38, 79-86 (2003).

74. Song, H. et al. Conversion of neuronal growth cone responses from repulsion to attraction by cyclic nucleotides. Science 281, 1515-1518 (1998).

75. Ramer, M. S., Priestley, J. V. \& McMahon, S. B. Functiona regeneration of sensory axons into the adult spinal cord. Nature 403, 312-316 (2000).

76. Qiu, J. et al. Spinal axon regeneration induced by elevation of cyclic AMP. Neuron 34, 895-903 (2002). This study, as well as reference 96 , demonstrates for the first time that elevation of CAMP in vivo, at the cell body, can induce spinal axon regeneration.

77. Cai, D. et al. Arginase I and polyamines are downstream from cyclic AMP in the pathway that overcomes inhibition of axonal regeneration by Mag and myelin in vitro. Neuron $\mathbf{3 5}$, 711-719 (2002)

78. Chu, P. J., Saito, H. \& Abe, K. Polyamines promote regeneration of injured axons of cultured rat hippocampal neurons. Brain Res. 673, 233-241 (1995).

79. Dornay, M., Gilad, V. H., Shiler, I. \& Gilad, G. M. Early polyamine treatment accelerates regeneration of rat sympathetic neurons. Exp. Neurol. 92, 665-674 (1986).

80. Kauppila, T., Stenberg, D. \& Porkka-Heiskanen, T. Putative stimulants for functional recovery after neural trauma: only spermine was effective. Exp. Neurol. 99, 50-58 (1988).

81. Banan, A., McCormack, S. A. \& Johnson, L. R. Polyamines are required for microtubule formation during gastric mucosal healing. Am. J. Physiol. 274, G879-885 (1998).

82. Kaminska, B., Kaczmarek, L. \& Grzelakowska-Sztabert, B. Inhibitors of polyamine biosynthesis affect the expression of genes encoding cytoskeletal proteins. FEBS Lett. 304 198-200 (1992)

83. Wolff, J. Promotion of microtubule assembly by oligocations: cooperativity between charged groups. Biochemistry $\mathbf{3 7}$, 10722-10729 (1998)

84. Williams, K. Interactions of polyamines with ion channels. Biochem. J. 325, 289-297 (1997).

85. Chao, J. et al. $\mathrm{N}^{1}$-dansyl-spermine and $\mathrm{N}^{1}$-(noctanesulfonyl)-spermine, novel glutamate receptor antagonists: block and permeation of $N$-methyl-p-aspartate receptors. Mol Pharmacol. 51, 861-871(1997)

86. Kashiwagi, K., Pahk, A. J., Masuko, T., Igarashi, K. \& Williams, $\mathrm{K}$. Block and modulation of $N$-methyl-o-aspartate receptors by polyamines and protons: role of amino acid residues in the transmembrane and pore-forming regions of NR1 and NR2 subunits. Mol. Pharmacol. 52, 701-713 (1997)

87. Williams, K., Zappia, A. M., Pritchett, D. B., Shen, Y. M. \& Molinoff, P. B. Sensitivity of the $N$-methyl-- - -aspartate receptor to polyamines is controlled by NR2 subunits. Mol. Pharmacol. 45, 803-809 (1994).

88. Cohen, S. (ed.) A Guide to the Polyamines (Oxford Univ. Press, New York, 1998).

89. Aizenman, C. D., Munoz-Elias, G. \& Cline, H. T. Visually driven modulation of glutamatergic synaptic transmission is mediated by the regulation of intracellular polyamines. Neuron 34, 623-634 (2002).
90. Ming, G., Henley, J., Tessier-Lavigne, M., Song, H. \& Poo, M. Electrical activity modulates growth cone guidance by diffusible factors. Neuron 29, 441-452 (2001).

91. Bregman, B. S. \& Goldberger, M. E. Anatomical plasticity and sparing of function after spinal cord damage in neonata cats. Science 217, 553-555 (1982).

92. Kunkel-Bagden, E., Dai, H. N. \& Bregman, B. S. Recovery of function after spinal cord hemisection in newborn and adult rats: differential effects on reflex and locomotor function. Exp. Neurol. 116, 40-51 (1992).

93. Neumann, S. \& Woolf, C. J. Regeneration of dorsal column fibers into and beyond the lesion site following adult spinal cord injury. Neuron 23, 83-91 (1999).

Shows that dorsal column axons will regenerate after a peripheral conditioning lesion without a peripheral nerve graft at the lesion site.

94. Richardson, P. M. \& Issa, V. M. Peripheral injury enhances central regeneration of primary sensory neurones. Nature 309, 791-793 (1984).

95. DeBellard, M. E., Tang, S., Mukhopadhyay, G., Shen, Y. J. \& Filbin, M. T. Myelin-associated glycoprotein inhibits axonal regeneration from a variety of neurons via interaction with a sialoglycoprotein. Mol. Cell. Neurosci. 7, 89-101 (1996).

96. Neumann, S., Bradke, F. Tessier-Lavigne, M. \& Basbaum, A. I. Regeneration of sensory axons within the injured spinal cord induced by intraganglionic cAMP elevation. Neuron 34, 885-893 (2002)

97. Bonilla, I. E., Tanabe, K. \& Strittmatter, S. M. Small prolinerich repeat protein $1 A$ is expressed by axotomized neurons and promotes axonal outgrowth. J. Neurosci. 22, 1303-1315 (2002).

98. Schreyer, D. J. \& Skene, J. H. Fate of GAP-43 in ascending spinal axons of DRG neurons after peripheral nerve injury: delayed accumulation and correlation with regenerative potential. J. Neurosci. 11, 3738-3751 (1991).

99. Schreyer, D. J. \& Skene, J. H. Injury-associated induction of GAP-43 expression displays axon branch specificity in rat dorsal root ganglion neurons. J. Neurobiol. 24, 959-970 (1993).

100. Bomze, H. M., Bulsara, K. R., Iskandar, B. J., Caroni, P. \& Skene, J. H. Spinal axon regeneration evoked by replacing two growth cone proteins in adult neurons. Nature Neurosci. 4, 38-43 (2001).

101. Scherer, S. S. \& Salzer, J. L. in Glial Cell Development; Basic Principles and Clinical Relevance (eds Jessen, K. R. \& Richardson, W. D.) 165-185 (Bios Scientific Publishers, Oxford, 1996).

102. Rapalino, O. et al. Implantation of stimulated homologous macrophages results in partial recovery of paraplegic rats. Nature Med. 4. 814-821 (1998).

103. Leskovar, A., Moriarty, L. J., Turek, J. J., Schoenlein, I. A. \& Borgens, R. B. The macrophage in acute neural injury: changes in cell numbers over time and levels of cytokine production in mammalian central and peripheral nervous systems. J. Exp. Biol. 203, 1783-1795 (2000).

104. Kelm, S. et al. Functional groups of sialic acids involved in binding to siglecs (sialoadhesins) deduced from interactions with synthetic analogues. Eur. J. Biochem. 255, 663-672 (1998).

105. Collins, B. E. et al. Sialic acid specificity of myelin-associated glycoprotein binding. J. Biol. Chem. 272, 1248-1255 (1997)

106. Vyas, A. A. et al. Gangliosides are functional nerve cell ligands for myelin-associated glycoprotein (MAG), an inhibitor of nerve regeneration. Proc. Natl Acad. Sci. USA 99, 8412-8417 (2002)

107. Yang, L. J. et al. Gangliosides are neuronal ligands for myelin-associated glycoprotein. Proc. Natl Acad. Sci. USA 93, 814-818 (1996)

108. Bandtlow, C. E. \& Loschinger, J. Developmental changes in neuronal responsiveness to the CNS myelin-associated neurite growth inhibitor NI-35/250. Eur. J. Neurosci. $\mathbf{9}$ neurite growth inhibitor

Acknowledgements

This review is dedicated to the memory of N. Kimura. I thank R. Persell for critically reading this manuscript and T. Spencer for creating the figures. Funding was provided by the NIH/NINDS/ RCMI/SNRP, the National Multiple Sclerosis Society, USA and the New York State Spinal Cord Initiative.

\section{(1) Online links}

\section{DATABASES}

The following terms in this article are linked online to: LocusLink: http://www.ncbi.nlm.nih.gov/LocusLink/ Gap43 | Mag | Nogo-A | Ngr | Omgp | p75 NTR | Sprrp1a 